\title{
Overview of Intergranular Fracture of Neutron Irradiated Austenitic Stainless Steels
}

\author{
Anna Hojná \\ Centrum Vyzkumu Rez (CVR), UJV Group, Rez 130, 25068 Husinec, Czech Republic; anna.hojna@cvrez.cz; \\ Tel.: +420-2-6617-3549
}

Received: 10 August 2017; Accepted: 16 September 2017; Published: 25 September 2017

\begin{abstract}
Austenitic stainless steels are normally ductile and exhibit deep dimples on fracture surfaces. These steels can, however, exhibit brittle intergranular fracture under some circumstances. The occurrence of intergranular fracture in the irradiated steels is briefly reviewed based on limited literature data. The data are sorted according to the irradiation temperature. Intergranular fracture may occur in association with a high irradiation temperature and void swelling. At low irradiation temperature, the steels can exhibit intergranular fracture at low or even at room temperatures during loading in air and in high temperature water $\left(\sim 300^{\circ} \mathrm{C}\right)$. This paper deals with the similarities and differences for IG fractures and discusses the mechanisms involved. The intergranular fracture occurrence at low temperatures might be correlated with decohesion or twinning and strain martensite transformation in local narrow areas around grain boundaries. The possibility of a ductile-to-brittle transition is also discussed. In case of void swelling higher than $3 \%$, quasi-cleavage at low temperature might be expected as a consequence of ductile-to-brittle fracture changes with temperature. Any existence of the change in fracture behavior in the steels of present thermal reactor internals with increasing irradiation dose should be clearly proven or disproven. Further studies to clarify the mechanism are recommended.
\end{abstract}

Keywords: intergranular fracture; austenitic stainless steel; high dose neutron irradiation; irradiation assisted stress corrosion cracking; void swelling; ductile-to-brittle transition temperature

\section{Introduction}

Intergranular (IG) fracture has always been a concern to design engineers because it is usually associated with low fracture energy and risk of unstable fracture. It applies in particular to the brittle intergranular fracture, classified based on fine fracture patterns on intergranular planes, which have to be excluded for the whole operation.

This paper focuses on the occurrence of intergranular fracture in irradiated austenitic stainless steels (ASSs) of 300 series (Types A304, A304L, A316, A316L, A321, A347 and Russian type $18 \mathrm{Cr}-10 \mathrm{Ni}-\mathrm{Ti})$, the structure materials of light-water-reactor core internals (RCI); see Table 1. Typically, these steels show stable ductile fracture behavior, even after irradiation, but under some circumstances they can exhibit intergranular fracture.

In the past, an occurrence of intergranular fracture in Type 304 and 316 austenitic stainless steels used in nuclear industry had been widely studied, e.g., [1]. At that time, the intergranular fracture mechanisms had been reviewed with emphasis to various types of embrittlement [2]. It is obvious that intergranular fracture occurs in material provided cracks initiate and grow preferentially on grain boundaries. On the atomic scale [2], intergranular fracture occurs if (i) decohesion (tensile separation of atoms) or (ii) shear movement or (iii) removal of atoms (diffusion or dissolution) in preference on grain boundary instead in the grain interiors. If some embrittling species are present on grain boundary, it could facilitate decohesion and consequently the brittle intergranular fracture (Figure 1a). 
Without embrittling species on grain boundary, the precipitation on it plays a decisive role in intergranular fracture; in this case, dimpled intergranular fracture (Figure 2a). The precipitation causes depletion of solute and consequentially the formation of precipitation-free zones adjacent to grain boundaries in precipitate hardened materials [2]. The intergranular fracture mode in materials with grain boundary precipitates and the precipitation-free zone is micro void coalescence in grain boundary zone; see Figure $2 \mathrm{~b}$. It can be occasionally characterized as brittle on the macro scale if the fine dimples were hard to observe; see Figure $1 \mathrm{~b}$. To differentiate between the brittle and dimpled IG fracture, high magnification of scanning electron microscopy (SEM) observation or transmission electron microscopy (TEM) replicas are necessary.

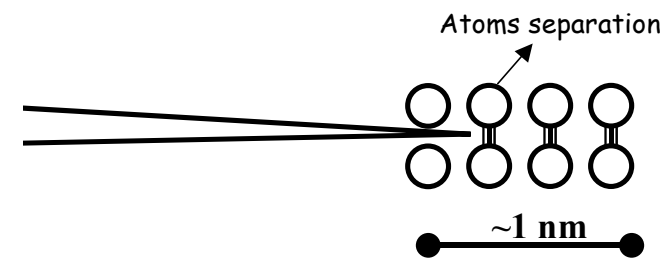

(a)

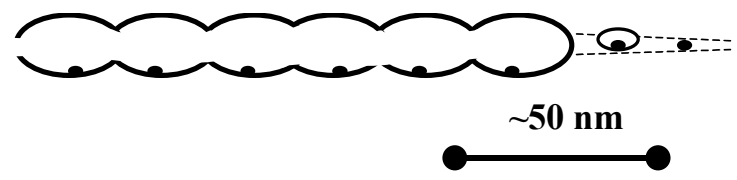

(b)

Figure 1. Schematic types of macro brittle intergranular fracture according [3]: (a) Atomically brittle intergranular fracture-featureless facets observed for high resolution SEM or TEM replicas often associated with embrittling segregation; (b) Nano-scale dimpled intergranular fracture-very shallow dimples-sometimes not resolved by SEM: can occur due to the micro void coalescence (MVC) process in the very narrow soft zone adjacent to grain boundary.

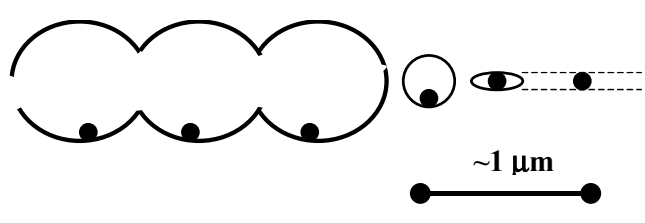

(a)

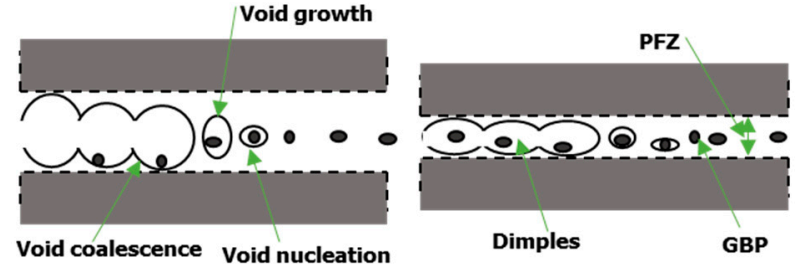

(b)

Figure 2. Schematic types of ductile intergranular fracture according [2,3]: (a) Ductile dimpled intergranular fracture-well-defined dimples at grain boundary usually resolved by SEM: can occur if large grain boundary precipitates as for wide soft zone adjacent to grain boundary; (b) Especially for precipitate harden alloys are given two diagrams illustrating dimple formation from voids at grain boundary with widely spaced grain boundary precipitate (GBP): (left) wide precipitate free zone (PFZ), (right) narrow PFZ; adapted and modified according [2].

Neutron irradiation produces radiation defects by collisions of neutrons with various atoms of the steel, which with time and with dependence on conditions form radiation damage (RD), i.e., Frank partial dislocation loops, cavities and precipitates, as well as stimulating chemical changes at structure boundaries causes radiation induced segregation (RIS) [4]. Focusing on grain boundaries, a very narrow zone, basically chromium depleted and nickel enriched, around grain boundary is created with respect to RIS [5] - an example is shown in Figure 3 [6]. Other species such as silicon are enriched on grain boundaries which may facilitate decohesion. Moreover, very fine precipitation, segregation and voids accumulation on grain and other boundaries of austenitic stainless steel microstructure, such as $\delta$-ferrite/austenite phase boundaries, is expected, but not yet unequivocally established. These microstructural effects result in changes of the material mechanical and fracture behavior. 
Table 1. The standard element composition of the austenitic stainless steels of reactor core internals (RCI), in wt. \%.

\begin{tabular}{|c|c|c|c|c|c|c|c|c|c|c|c|c|c|}
\hline Steel & C & Mn & $\mathrm{Si}$ & $\mathrm{S}$ & $\mathbf{P}$ & $\mathrm{Ni}$ & $\mathrm{Cr}$ & Mo & $\mathrm{Nb}$ & $\mathrm{Ti}$ & Co & $\mathrm{Cu}$ & $\mathbf{N}$ \\
\hline A304L & Max. 0.035 & Max. 2.0 & Max. 1.0 & Max. 0.03 & Max. 0.04 & $9.0-11.0$ & $18.5-20.0$ & - & - & - & Max. 0.10 & Max. 0.10 & Max. 0.08 \\
\hline A316 & Max. 0.80 & Max. 2.0 & Max. 1.0 & Max. 0.03 & Max. 0.04 & $10.0-14.0$ & $16.0-18.0$ & $2.25-3.00$ & - & - & Max. 0.10 & Max. 0.10 & Max. 0.08 \\
\hline A316L & Max. 0.030 & Max. 2.0 & Max. 1.0 & Max. 0.03 & Max. 0.045 & $10.0-14.0$ & $16.0-18.5$ & $2.00-3.00$ & - & - & Max. 0.10 & Max. 0.10 & Max. 0.08 \\
\hline A321 & Max. 0.80 & Max. 2.0 & Max. 1.0 & Max. 0.03 & Max. 0.045 & $9.0-12.0$ & $17.0-19.0$ & - & - & $\operatorname{Min} 0.30 \operatorname{Max} 0.70$ & Max. 0.05 & Max. 0.30 & Max. 0.05 \\
\hline A347 & Max. 0.40 & Max. 2.0 & Max. 1.0 & Max. 0.02 & Max. 0.035 & $9.0-12.0$ & $17.0-19.0$ & - & Max. 0.065 & - & Max. 0.20 & - & Max. 0.08 \\
\hline $18 \mathrm{Cr}-10 \mathrm{Ni}-\mathrm{Ti}$ & Max. 0.08 & Max. 2.0 & Max. 0.8 & Max. 0.02 & Max. 0.035 & $9.0-11.0$ & $17.0-19.0$ & - & - & Min. 5xC Max. 0.70 & Max. 0.05 & Max. 0.30 & Max. 0.05 \\
\hline
\end{tabular}




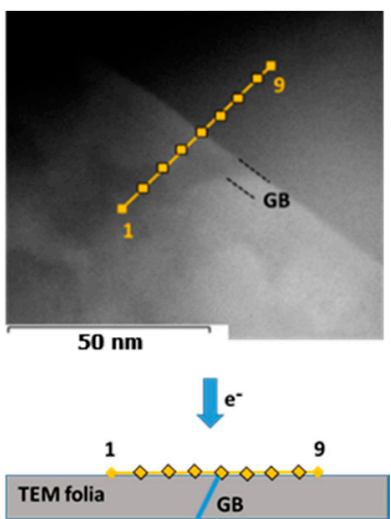

(a)

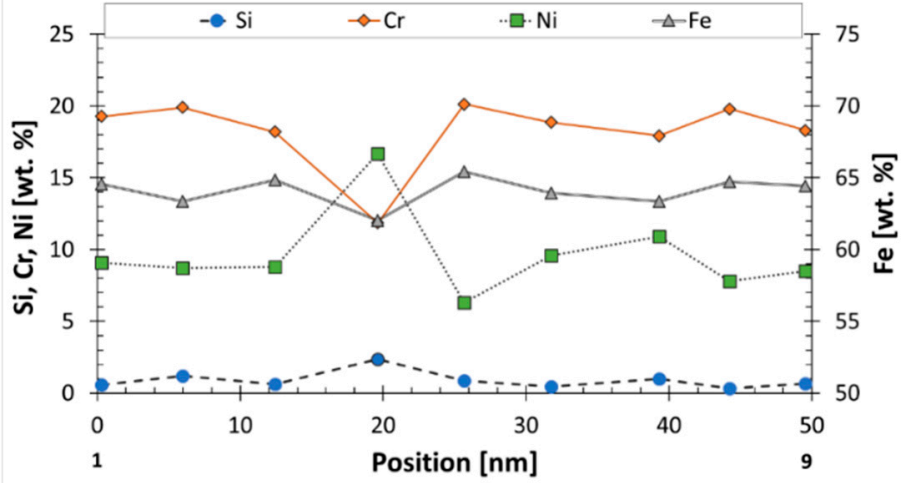

(b)

Figure 3. Scanning TEM Energy-dispersive X-ray spectroscopy (EDS) point analyses (from 1 to 9) in a marked line across a high-angle grain boundary of in-service irradiated $18 \mathrm{Cr}-10 \mathrm{Ni}$-Ti of Russian PWR (WWER) RCI (5.2 dpa): (a) schematic showing position of the grain boundary (GB) in the TEM folia; (b) Depleted Cr and enriched Ni, Si was observed [6]. Copyright 2018 by The Minerals, Metals \& Materials Society. Used with permission.

This paper aims to elaborate on the issue of intergranular fracture of irradiated steels because it seems that avoiding such fractures in the future is not well understood. In the past, a very comprehensive review was published [5], dealing with radiation-induced material changes and susceptibility to IG failure of LWR core internals, focused on the explanation of Intergranular Stress Corrosion Cracking (IGSCC) in water environments, but did not mention IG fracture in inner environments. In recent papers [7,8], deformation and fracture of ASSs irradiated to low doses were studied in detail. Moreover, a ductile-to-brittle transition possibility and low temperature embrittlement with increasing neutron exposure and the intergranular fracture kinetics need to be evaluated.

\section{IG Fracture Occurrence in Relation to Irradiation Temperature}

Considering the fracture behavior of the irradiated steel influenced by a variety of factors, like the irradiation conditions, i.e., irradiation temperature $\left(T_{i r}\right)$, neutron dose, flux and energy spectrum, as well as on initial material conditions (microstructure, composition, etc.) and load variables such as test temperature $\left(\mathrm{T}_{\mathrm{t}}\right)$, constraint and strain rate [9], the irradiation temperature appears to be the most important. Naturally, the level of void swelling is highly dependent on temperature.

\subsection{Low Temperature Irradiation}

The neutron irradiation under commercial Pressurized (PWR) and Boiling (BWR) water reactors reactor vessel conditions, where $\mathrm{T}_{\mathrm{ir}}$ is below $360^{\circ} \mathrm{C}$, is classified as low temperature irradiation. At these temperatures, the neutron exposure causes only very limited void swelling. It means that a limited amount of $\mathrm{H} / \mathrm{He}$ filled voids of nano size form and grow inside the microstructure. All void swelling observed to date in PWRs, up to $80 \mathrm{dpa}$ in flux thimble tubes (FTT), has been relatively low, $<1 \%$ [10]. Under these conditions, austenitic stainless steels of reactor core internals undergo slow permanent changes of material behavior with time. Namely, the capability of plastic deformation is restricted, causing an increase of strength and a loss of ductility and fracture resistance. The behavior is more evident with increasing the irradiation dose, but the material behavior stabilizes on a saturation level at about 5-15 displacement per atom (dpa). From the fracture point of view, the saturation of fracture toughness was referred from $15 \mathrm{dpa}$ up to $85 \mathrm{dpa}$ on level of $\mathrm{K}_{\mathrm{IC}}=38 \mathrm{MPa} \sqrt{ } \mathrm{m}$, which is used as the disposition line [11,12]. Such a value would be taken for a typical brittle fracture in case 
of non-irradiated materials. However, the irradiated austenitic stainless steels usually preserve their ductile fracture behavior if loaded under room up to irradiation temperatures [11,13].

According to [14], the loss of fracture toughness and severe degradation in tearing modulus, the slope of the fracture resistance curve, observed in austenitic stainless steels irradiated at the temperatures mentioned above are consistent with a change in fracture mode with increasing dose, transitioning from a ductile-dimple process to a shear decohesion process where severe dislocation channeling and channel fracture predominate. The channel fracture is a transgranular (TG) shear fracture following the dislocation channel with plate-like appearance. Whereas dislocation channels spread over all grains, the size of the plate-like facets can be comparable to grain size. Because of shear character, the channel fracture plate tilt to applied load. Therefore, it is sometimes difficult to distinguish between channel and intergranular fractures.

Temperature and strain rate dependence of fracture mode deserve special attention because several papers reported intergranular cracking. In the paper [15], IG fracture was observed at $310^{\circ} \mathrm{C}$ in a test specimen of 7 dpa PWR irradiated A304 steel of a rod cluster control assembly tested in argon gas applying very slow strain rate $\left(10^{-7} \sim 10^{-8} \mathrm{~s}^{-1}\right)$; IG fracture was revealed at the control rod field surface (likely Irradiation Assisted Stress Corrosion Cracking (IASCC) as mentioned later).

The other case $[16,17]$ of the presence of IG fractures was observed on the specimens of flux thimble tubes (15\%CW A316) at low and room temperatures in impact tests (Figure 4). These FTTs were irradiated in $290-325{ }^{\circ} \mathrm{C}$ at PWR to doses from 11 to $73 \mathrm{dpa}$. He concentration in the steel was estimated to be approximately 0.07 at. \% [18]. At higher test temperatures, the impact fracture mode changed to a mixed one consisting of ductile dimpled and channel fractures. Some IG features appeared also in the $73 \mathrm{dpa}$ material tensile tested with very slow strain rate at $320^{\circ} \mathrm{C}$ in air.

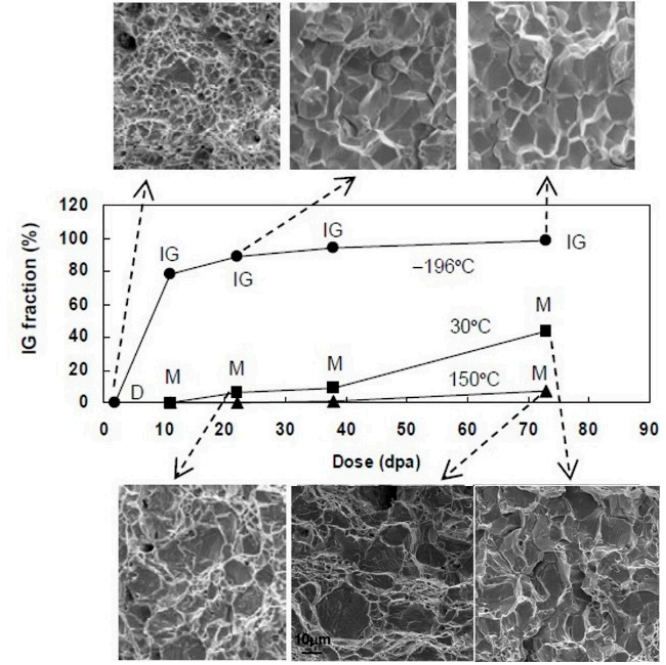

(a)

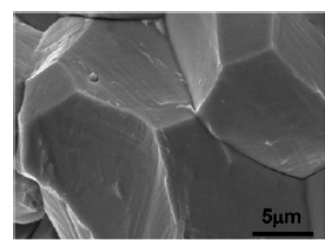

(b)

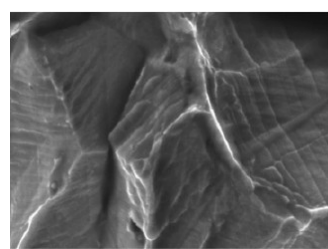

(d)

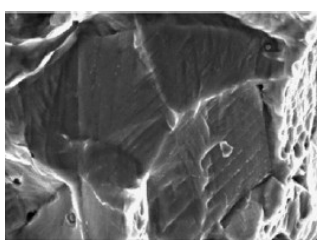

(c)

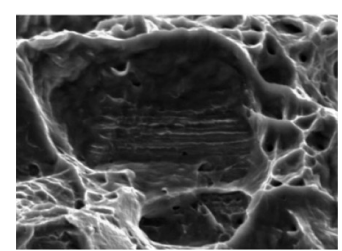

(e)

Figure 4. Fracture modes of impact tests with irradiated A316 CW (IG: intergranular, M: mixed mode, D: ductile dimple, grain size 20-30 $\mu \mathrm{m} ; \mathrm{He} \sim 0.07$ at. \%): (a) Summary of IG fraction of impact tests at $-196,30$ and $150^{\circ} \mathrm{C}$ showing changing fracture appearance [16] (Copyright 2009 by The Atomic Energy Society of Japan. Used with permission.); SEM micrographs showing some details of intergranular (IG) and channel facets in fracture (b) $73 \mathrm{dpa},-196^{\circ} \mathrm{C}$, (c) $73 \mathrm{dpa}, 30^{\circ} \mathrm{C}$, (d) $11 \mathrm{dpa},-196{ }^{\circ} \mathrm{C}$, (e) $38 \mathrm{dpa}$, $150{ }^{\circ} \mathrm{C}$ [17]. Reproduced with the courtesy of K. Fukuya. Elsevier reuse license has been granted.

Moreover, IG fracture occurrence at room temperature had been studied [19] in highly irradiated stainless steels, instrument tubes from a PWR and a BWR removed from service after 29 and 20 years, respectively (doses up to $\sim 80 \mathrm{dpa}$ ). The materials exposed were cold worked Type 316 taken from flux thimble tubes of PWR and Type 304 taken from a wide range neutron monitor of BWR. 
Both components revealed cracks after deformation at close to room temperature and the cracks were intergranular. Following laboratory testing with specimens of the materials, IG fracture was observed on a part of the fracture surface at room temperature (Figure 5), while at the elevated temperatures $\left(288^{\circ} \mathrm{C}, 320^{\circ} \mathrm{C}\right)$, ductile fracture resulted. The room temperature tensile tests showed unusual high elongations and flat stress-strain curves which could indicate deformation likely with phase transformation to strain-induced martensite.

Also, a previous paper [20] referred to IG fracture mode occurrence. IG facets mixed with ductile dimples were observed on fracture toughness specimens made of PWR flux thimble tubes $\left(15 \% \mathrm{CW}\right.$ A316, $\left.\mathrm{T}_{\mathrm{ir}} 290-320^{\circ} \mathrm{C}, 65 \mathrm{dpa}\right)$ tested at room temperature (Figure 6), but no intergranular fracture was found at $320^{\circ} \mathrm{C}$ test. In testing of tensile specimen made of the tubes, mixed fractures prevailed, i.e., ductile dimples with many channel fracture facets found at room temperature unlike fully ductile fracture modes at $320^{\circ} \mathrm{C}$. These results indicated that the intergranular fracture occurrence was dependent on temperature and on specimen stress-strain state.

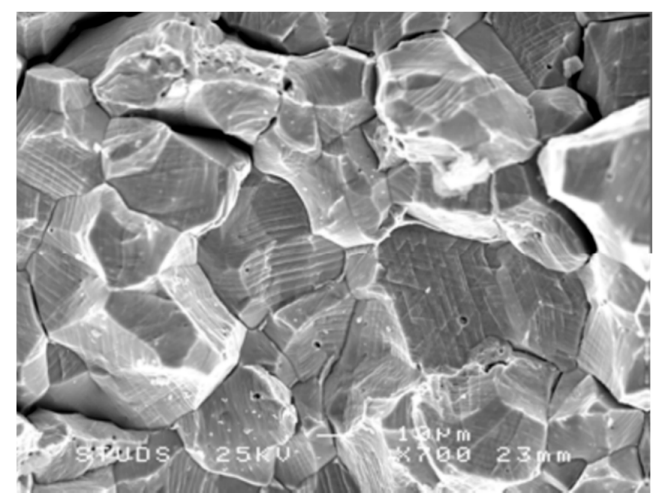

Figure 5. IG fracture of thin tensile specimens from the wide range neutron monitor guide tube of A304 steel irradiated in BWR to $\sim 80 \mathrm{dpa}$ and tensile tested at room temperature [19]. Reproduced with the courtesy of A. Jenssen and Société Française d'Énergie Nucléaire (SFEN).

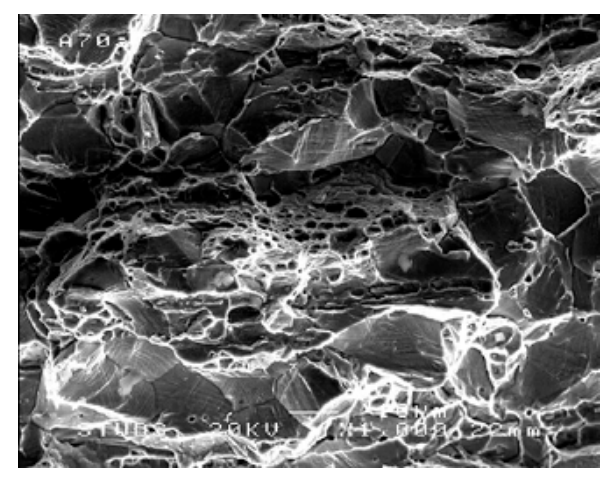

Figure 6. IG and ductile dimpled fracture of pin-loading tension specimen of a flux thimble tube (FTT), made from cold drawn A316, irradiation to $65 \mathrm{dpa}$ in a PWR; fracture toughness test in air at room temperature [20]. Reproduced with the courtesy of A. Jenssen and Société Française d'Énergie Nucléaire (SFEN).

In [17], a compilation of fracture data gathered on A304 and CWA316 irradiated steels was performed $[15,17,20-26]$ : it appeared that there are two different conditions for the occurrence of IG modes in stainless steels irradiated in PWRs: Low Temperature High strain Rate (LTHR) condition and High Temperature Low strain Rate (HTLR) condition. The sensitivity to IG mode was higher for higher doses in both conditions, and becomes higher for lower temperature in LTHR conditions and for higher temperature and lower strain rate in HTLR conditions. 
Another observation of the IG fracture was referred at irradiated Ti stabilized austenitic stainless steel $18 \mathrm{Cr}-10 \mathrm{Ni}-\mathrm{Ti}$, in-service irradiated in WWER reactor core to $2-11 \mathrm{dpa}$ at $260-330{ }^{\circ} \mathrm{C}$. IG fractures were found on fracture mechanics specimens broken to open in nitrogen vapor at about $-100{ }^{\circ} \mathrm{C}$ (Figures 7 and 8) [3].

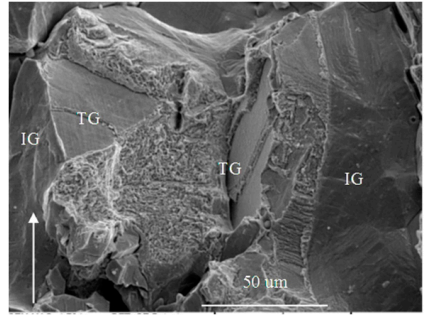

(a)

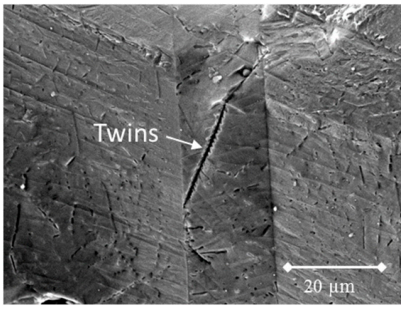

(b)

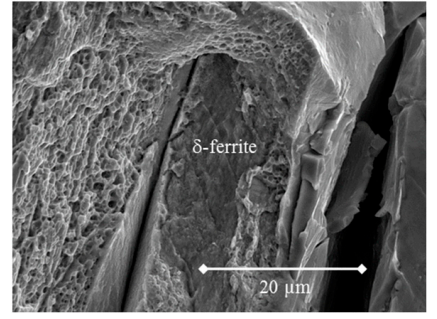

(c)

Figure 7. Fracture modes of the $2.4 \mathrm{dpa}$ irradiated $18 \mathrm{Cr}-10 \mathrm{Ni}-\mathrm{Ti} \mathrm{CT}$ specimen if broken to open in nitrogen vapor at about $-100{ }^{\circ} \mathrm{C}$; arrow indicates the crack growth direction [3]: (a) Mixed IG with transgranular (TG) fracture connected by bridges of cleavage and ductile shear; (b) Twinning on grain boundary; (c) Fracture around a large $\delta$-ferrite particle showing cleavage of the particle and secondary cracks close to ductile ridges.

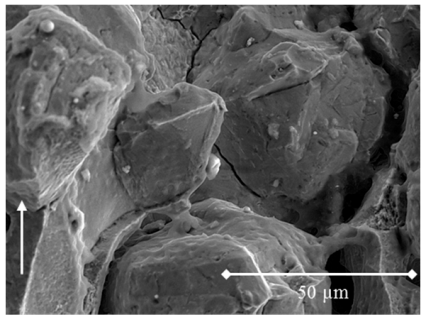

(a)

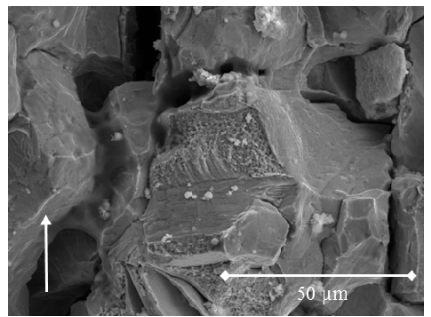

(b)

Figure 8. Complex brittle IG and TG fractures of the $5.2 \mathrm{dpa}$ irradiated $18 \mathrm{Cr}-10 \mathrm{Ni}-\mathrm{Ti} \mathrm{CT}$ specimen if broken to open in nitrogen vapor at about $-100^{\circ} \mathrm{C}$; arrows indicate the crack growth direction: (a) one specimen; (b) second specimen [3].

Another type of IG fracture appears in IASCC, observed if the irradiated steel is loaded in contact with a high temperature water environment which is used as the primary coolant of BWR/PWR/WWER, e.g., $[5,13,25,27,28]$. This is a very special type of IG fracture, whose mechanism is not yet sufficiently understood (Figure 9).

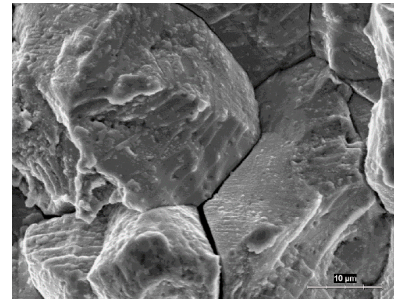

(a)

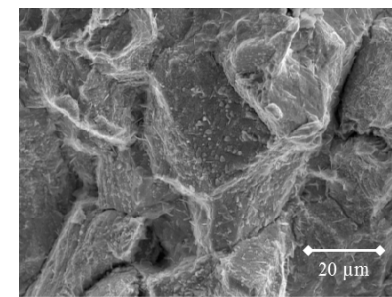

(b)

Figure 9. The fracture surface appearance showing IG fracture of Irradiation Assisted Stress Corrosion (IASCC) in tensile specimens made from irradiated $18 \mathrm{Cr}-10 \mathrm{Ni}$-Ti steel and SSRT by $1 \times 10^{-7} \mathrm{~s}^{-1}$ at high temperature water at $320^{\circ} \mathrm{C}$ [13]: (a) the specimen irradiated in the fast reactor $\left(\mathrm{BOR}-60, \mathrm{~T}_{\mathrm{ir}}=320^{\circ} \mathrm{C}\right.$, $12.6 \mathrm{dpa}$ ); (b) the specimen fabricated of the in-service irradiated steel (WWER, $\mathrm{T}_{\mathrm{ir}}=320^{\circ} \mathrm{C}, 5.2 \mathrm{dpa}$ ). Copyright 2011 by The Minerals, Metals \& Materials Society. Used with permission. 


\subsection{Intermediate Temperature of Irradiation}

The temperatures ranging between $360^{\circ} \mathrm{C}$ and $450{ }^{\circ} \mathrm{C}$ are considered intermediate temperatures of irradiation. Here, void population development becomes a significant part of radiation damage.

Owing to void swelling at high doses ( $\geq 50 \mathrm{dpa}$ ), solution annealed austenitic steels undergo a transition from the transgranular ductile dimpled fracture behavior to transgranular channel fracture; intermediate exposures (10 to $50 \mathrm{dpa}$ ) produce a mixed mode of fracture [29]. The appearance of channel fractures was correlated with the onset of highly localized deformation of dislocation channeling and by implication the development of a high density of shearable defects of radiation damage [29]. A development of the fracture appearance of A304 with increasing neutron fluence is shown in Figure 10 [30,31].

Several other examples illustrate the fracture behavior of ASSs irradiated in the temperatures. The first reference dealt with behavior of $20 \% \mathrm{CW}$ A316 steel irradiated to about 55 dpa (in EBR-II fast reactor at $377-400{ }^{\circ} \mathrm{C}$ ) [32]. The specimens were loaded at $230-650^{\circ} \mathrm{C}$ in the fracture toughness test using a standard test rate; at $230-540{ }^{\circ} \mathrm{C}$, tests showed mixed transgranular fracture including islands of channel fracture; at $650{ }^{\circ} \mathrm{C}$, ductile IG fracture was observed [32].

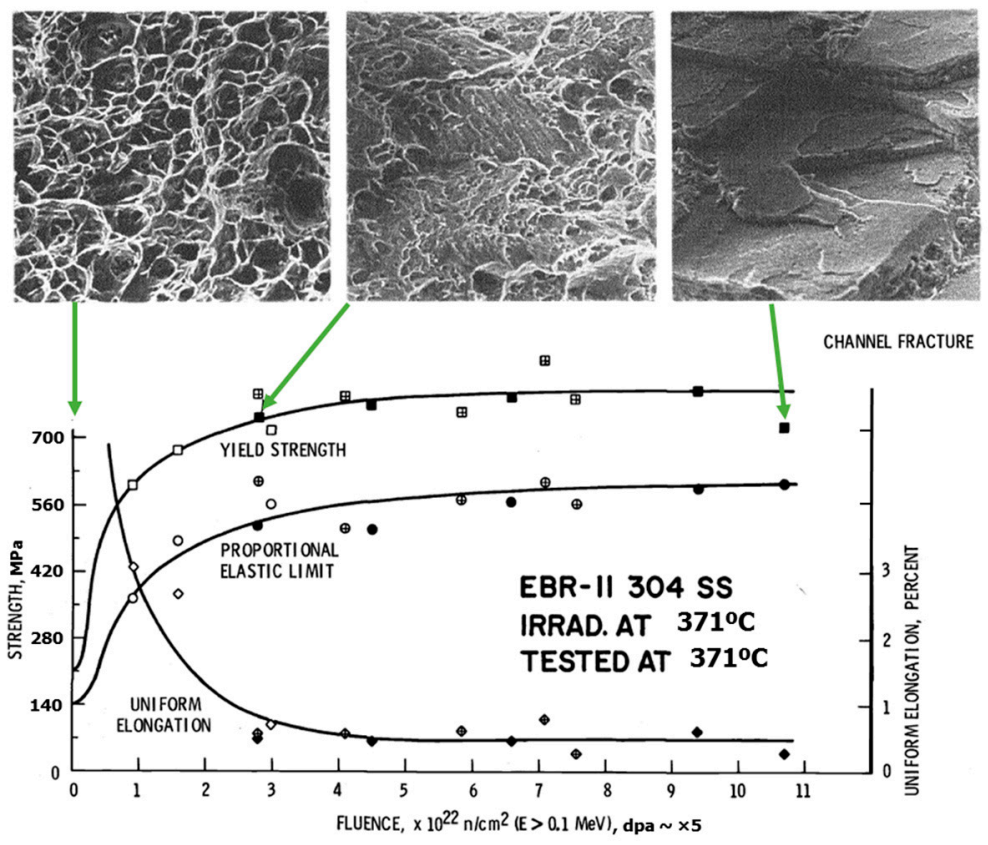

Figure 10. Effect of irradiation fluence on the yield strength and the uniform elongation of annealed 304 austenitic stainless steel (ASS) showing changing fracture appearance owing to increased plastic flow localization [30]. Note the channel fracture at $\sim 54 \mathrm{dpa}$. Adapted and modified according [31] with courtesy of F. A. Garner.

Another reference studied the behavior of $20 \% \mathrm{CW}$ A316 irradiated to about $64-78 \mathrm{dpa}$ (EBR-II at $385-460{ }^{\circ} \mathrm{C}, \sim 3-8 \%$ of void swelling) [31,33]. At 205 and $460{ }^{\circ} \mathrm{C}$ testing by tensile tests $\left(6 \times 10^{-4} \mathrm{~s}^{-1}\right)$, the fracture mode observed was mixed ductile with the channel fracture (Figure 11). 


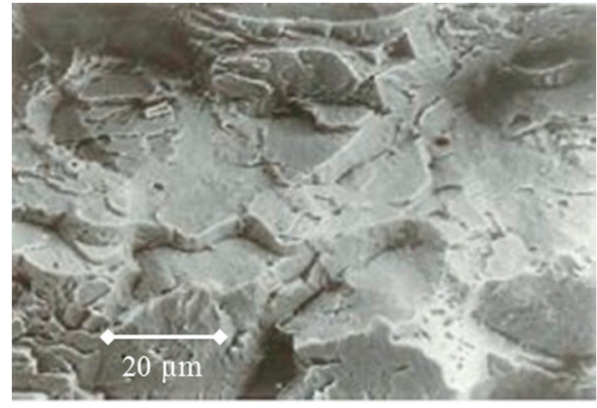

(a)

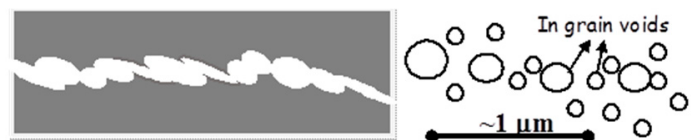

(b)

Figure 11. Example of channel fracture of: (a) $20 \% \mathrm{CW}$ A316 irradiated at $385^{\circ} \mathrm{C}$ to $\sim 64 \mathrm{dpa}$ in EBR-II and tensile tested by $6 \times 10^{-4} \mathrm{~s}^{-1}$ at $205{ }^{\circ} \mathrm{C}$. Adapted and modified according [31] with courtesy of F. A. Garner. The material exhibited $\sim 3-8 \%$ of void swelling. Courtesy of F. A. Garner [31]; (b) Scheme of the TG channel fracture owing shear of bridges linking up the voids according to the TEM image in [33].

The other example shows the behavior of Russian 18Cr-10Ni-Ti steel [34] (Figure 12). The fracture appeared mostly IG after the irradiation in BOR-60 at $400-450{ }^{\circ} \mathrm{C}$ and ruptured in tensile tests at RT and $290{ }^{\circ} \mathrm{C}$. The steel contained $3-13 \%$ void swelling.

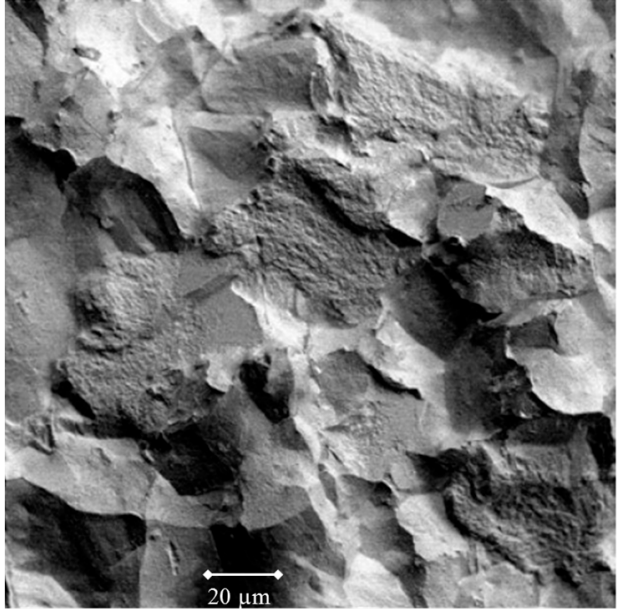

(a)

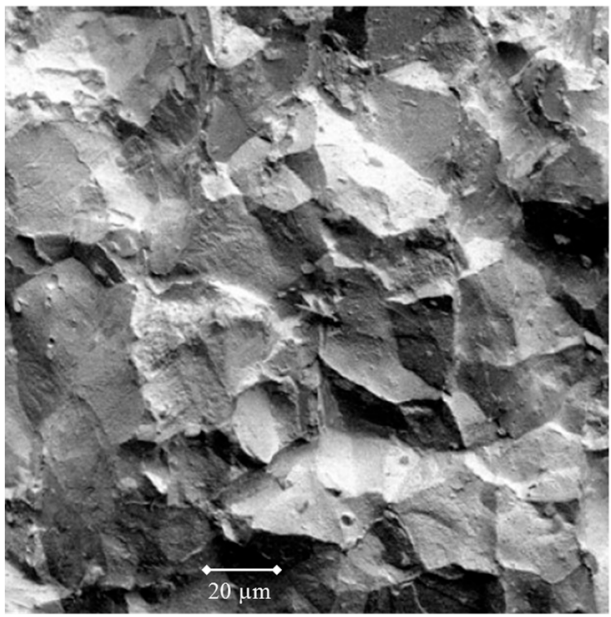

(b)

Figure 12. Fracture appearance of $18 \mathrm{Cr}-10 \mathrm{Ni}-\mathrm{Ti}$ steel specimens irradiated at BOR-60 at $400-450{ }^{\circ} \mathrm{C}$ to 49 dpa (3-13\% void swelling); showing IG and channel facets after tensile tests at: (a) $20{ }^{\circ} \mathrm{C}$; (b) $290^{\circ} \mathrm{C}$ [34]. Reproduced with courtesy of V. S. Neustroev. Copyright 2009 by The American Society of Mechanical Engineers (ASME). Acknowledgment to use with the permission.

\subsection{High Irradiation Temperature}

At the higher temperatures $\left(450{ }^{\circ} \mathrm{C}\right.$ up to $\left.750{ }^{\circ} \mathrm{C}\right)$ typical for irradiation in fast reactors, intensive void swelling development has to be considered in addition to other radiation damage structures. He produced by transmutation rapidly segregates to grain boundaries during irradiation [5], but sizable voids are also present inside the grains.

The irradiated materials undergo reduction of strain hardening and helium embrittlement effects which act synergistically to decrease ductility. The fractures of irradiated austenitic stainless steels at test temperature $T_{t}$ equal to or above $T_{i r}$ were often found to be IG, formed by the stress-induced growth and linking of grain boundary cavities, the characteristics of high-temperature helium embrittlement [4] producing dimpled IG fracture [29]. 
The $20 \% \mathrm{CW}$ A316 steel irradiated to about 78 dpa (EBR-II) at $460{ }^{\circ} \mathrm{C}$, having about $3-8 \%$ void swelling, tested at RT exhibited very low uniform and total elongation (1.9\%) [33]. The tensile test specimen showed unusual fracture appearance: visually flat and perpendicular to load axis, but in high magnification the whole surface coved by round nano-voids, that remained intact without any sign of smearing indicating brittle behavior of surrounding matrix (Figure 13) [31,33]. This type of fracture was called "quasi-cleavage". On the specimens tested at higher temperature, channel fracture prevailed.

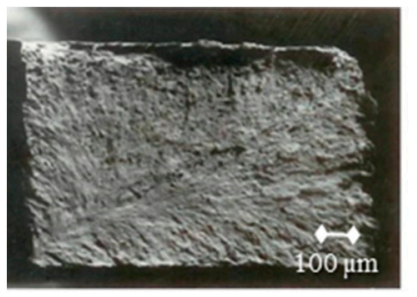

(a)

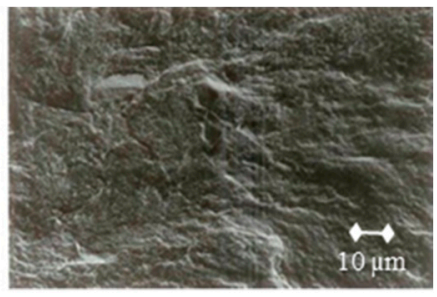

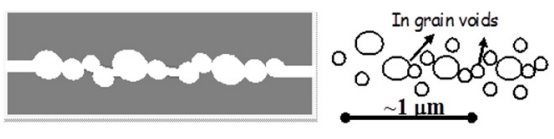

(b)

Figure 13. Quasi-cleavage of (a) specimen of $20 \% \mathrm{CW}$ A316 (EBR-II, $460{ }^{\circ} \mathrm{C}, 78 \mathrm{dpa}, 3-8 \%$ of void swelling) after tensile test at RT. Detail in right showing many fine voids. Adapted and modified according [31] with courtesy of F. A. Garner. (b) Scheme of the Quasi-cleavage fracture mechanisms-TG fracture owing cleavage rupture of bridges linking up micro-scale voids emphasizing that they are not deformed.

Similar observation had been referred in [35] for 18Cr-10Ni-Ti steel wrappers irradiated in BOR-60 at $450-550{ }^{\circ} \mathrm{C}$, where values of swelling reached more than $15-20 \%$, and specimens tested at $T_{t}$ below $T_{i r}$ at which the plasticity (the uniform elongation) was essentially zero. The same steel specimens tested at $T_{t}$ showed uniformly sized micro dimples on the fracture surface; it is likely the voids are little deformed by creep (see Figure 14).

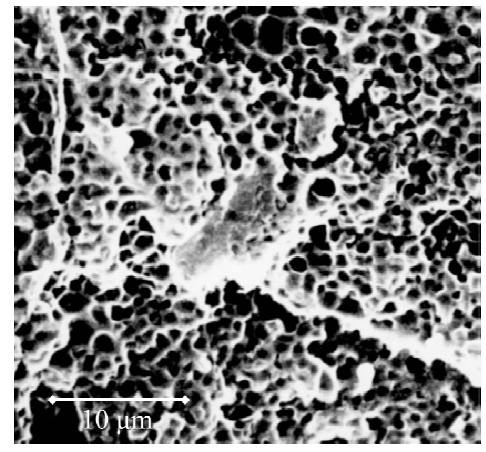

(a)

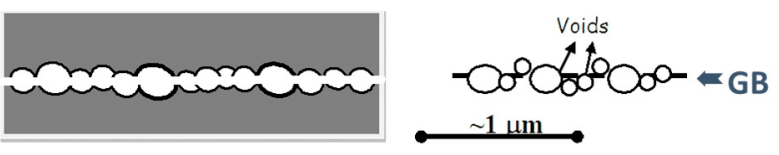

(b)

Figure 14. The fracture of the steel containing a higher than $15 \%$ void swelling at temperature $T_{t} \approx T_{\text {ir }}$ : (a) $18 \mathrm{Cr}-10 \mathrm{Ni}-\mathrm{Ti}$ ASS irradiated at BOR-60 to 72 dpa with $26 \%$ void swelling; after tensile test at $450-550{ }^{\circ} \mathrm{C}$. Reproduced from [35] with courtesy of V. S. Neustroev. Elsevier reuse license has been granted. (b) Scheme of the fracture mechanism emphasizing that the void boundaries are deformed by creep and linked up.

A summary of the referred observations of the IG fracture occurrence in relation to the irradiation and test temperatures illustrates a schematic in Figure 15. 


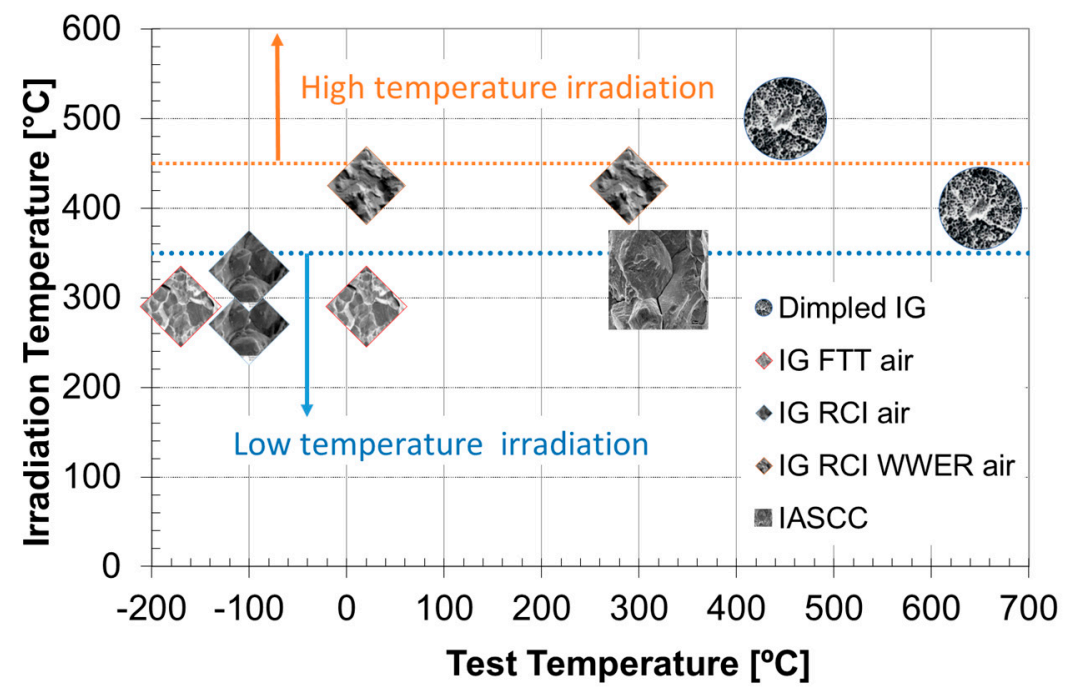

Figure 15. The irradiation vs. test temperature schematic showing the occurrence of IG fracture in neutron irradiated ASSs, as referred to in [3,9,14,16-20,32-35]. Blue and orange dotted horizontal lines separate the low, intermediate and high temperature irradiation areas. IG is intergranular, FTT is Flux thimble tube, RCI is Reactor Core Internals, IASCC is Irradiation Assisted Stress Corrosion Cracking.

\section{Key Points of Discussion}

\subsection{Plastic Deformation}

Without a doubt, a change of plastic behavior of the ASS with increased irradiation contributes to the change of the fracture mode. The typical deformation mode of un-irradiated ASS is dislocation glide. According to a deformation map, calculated for the type of steels straining very slow $\left(1 \times 10^{-8} \mathrm{~s}^{-1}\right)$, dislocation glide is the dominant mechanism at low temperatures up to about $550{ }^{\circ} \mathrm{C}$, before dominating dislocation creep mechanism [36]. The map calculated for the steels irradiated to low dose ( $1 \mathrm{dpa}$ ) discovered a significant change: twinning deformation dominates at low temperatures up to room temperature, where dislocation glide becomes the dominant mechanism; above $300{ }^{\circ} \mathrm{C}$, dislocation creep dominates the deformation. It corresponds to the observation of deformation modes in the irradiated steels. For example, analysis of deformation microstructures in 1-5 dpa ion-irradiated stainless steel, simulating the low temperature neutron irradiation at $300{ }^{\circ} \mathrm{C}$, showed twinning to be the prevailing deformation mode at room temperature [37]. The material was pulled in tension up to $10 \%$ strain at strain rates of $2 \times 10^{-4}$ and $2 \times 10^{-6} \mathrm{~s}^{-1}$. No twinning was observed for the un-irradiated material in the same condition.

With higher irradiation, the deformation becomes more localized; dislocation glide is limited to dislocation channels. It was observed that dislocation channeling occurred at room temperature under slow strain rate conditions; however, it predominated at $288^{\circ} \mathrm{C}$ [37]. Another result comes from examination of the AJ316 specimens neutron irradiated to $7 \mathrm{dpa}$ [38]. The irradiation in the Oak Ridge research reactor produced $\sim 80 \mathrm{ppm}$ of He atoms in the steel. In the specimen irradiated at $60{ }^{\circ} \mathrm{C}$ and tensile tested at $25^{\circ} \mathrm{C}$ at a strain rate of $4 \times 10^{-4} \mathrm{~s}^{-1}$, the deformation microstructure consisted of twins, elongated faulted loops, and lath and twin martensite phase. In the specimen irradiated and tested at $330^{\circ} \mathrm{C}$ with strain rates of $4 \times 10^{-4}$ and $4 \times 10^{-6} \mathrm{~s}^{-1}$, in addition to these features, dislocation channeling was also observed. It indicated that twinning was the predominant deformation mode at slower strain rate and dislocation channeling was favored at higher temperature.

It is well known that the microstructure of most ASSs is not thermodynamically stable around RT. Therefore, applied stress or plastic deformation may induce a diffusionless transformation of austenite to martensite, usually occurring at temperatures below RT and in a specific range of strain 
rates [39]. Plastic strain aids the transformation by formation of energetically favorable nucleation sites, which involve intersections of shear bands consisting of stacking faults and mechanical twins.

After irradiation, the sensitivity of ASSs to strain induced martensite formation likely increases, owing to chemical changes of grain boundaries dropping of the stacking fault energy (SFE,) and with presence of void swelling. The presence of strain-induced martensite at the deformation of highly irradiated ASS had been documented several times [33,40-42]. Test temperature and strain rate were decisive. The strain martensite was observed at RT: In the case of the $20 \% \mathrm{CW} \mathrm{A316}$ irradiated at intermediate $\mathrm{T}\left(385^{\circ} \mathrm{C}\right)$, containing $\sim 10 \%$ void swelling [33], the strain martensite was observed by TEM after tensile and fracture toughness testing at RT. Results of newer studies [40,41] confirmed the involvement of the $\gamma \rightarrow \alpha$ transformation to below or at RT plastic deformation of ASSs irradiated at low $\mathrm{T}$ to high doses. It was studied 12Cr18Ni10Ti steel (Russian analog of A321) irradiated at BN350 fast reactor $\left(290-310^{\circ} \mathrm{C}\right)$ to $13 \mathrm{dpa}$ at $-40{ }^{\circ} \mathrm{C}$ and $55 \mathrm{dpa}$ at $20^{\circ} \mathrm{C}$. Also, $12 \mathrm{dpa}$ specimen of $08 \mathrm{Cr} 16 \mathrm{Ni} 11 \mathrm{Mo} 3$ (Russian analog of A316) showed that the transformation occurred at $-115^{\circ} \mathrm{C}$. Also, 26 dpa specimen from $18 \mathrm{Cr}-10 \mathrm{Ni}$-Ti steel irradiated at intermediate $\mathrm{T}\left(423^{\circ} \mathrm{C}\right)$ exhibited the characteristic wave on tensile test curve at $20^{\circ} \mathrm{C}$, where the content of ferrite, measured in-situ, increased almost to $30 \%$.

As mentioned above, the martensite was observed after standard and slow tests at $25{ }^{\circ} \mathrm{C}$ $\left(\mathrm{T}_{\mathrm{ir}}=60^{\circ} \mathrm{C}\right)$ and after slow strain rate tests at $330^{\circ} \mathrm{C}\left(\mathrm{T}_{\mathrm{ir}}=330{ }^{\circ} \mathrm{C}\right)$ [38]. Moreover, in [42], the $30 \mathrm{dpa}$ irradiated A304 stainless steel extracted from the PWR Chooz A plant center filler assembly has been the subject of slow tensile testing $\left(1 \times 10^{-7} \mathrm{~s}^{-1}\right)$ performed to fracture in argon gas of $340^{\circ} \mathrm{C}$. Post-test analyses showed dislocation channels, heavy deformation in crisscrossing clear channels containing epsilon and twins as well as regions of developed strain martensite.

\subsection{Mechanism of IG Fracture}

A chemical composition and crystallographic structure of grain boundaries in conjunction with segregation affects strongly the fracture characteristics of materials ([43], p. 180). A typical distribution of grain boundaries of annealed ASS of RCI contains about $50 \%$ general high angle boundaries (GHAB), earlier called random ([43], p. 12), and about $50 \%$ special boundaries, which include low-angle, $\Sigma 3$ twin, $\Sigma 9$ and $\Sigma 27$ boundaries [44]. The number of experimental evidence suggests that susceptibility of non-irradiated stainless steels to IG fracture depends on the structure of the grain boundaries. It is the spatial distribution of low $\Sigma$ CSL boundaries relative to GHAB which affects susceptibility to IG fracture [45].

Considering the basic types of IG fracture mentioned in the introduction, the fracture mechanism may explain basically two types as follows:

1. The atomically brittle intergranular fracture (Figure 1a) arising from (a) decohesion triggered by the segregation on grain boundary; or (b) austenite to ferrite transformation, e.g., strain martensite formation, due to chemical changes in composition in grain boundary region and its failure, or (c) nano-scale $\mathrm{H} / \mathrm{He}$ filled cavities at grain boundary link up and brittle failure of bridges in between.

2. The nano-scale dimpled intergranular fracture (Figure 1b) resulting from (a) twinning limited to grain boundary region because the temperature is not high enough to activate twinning deformation in grains; or (b) nano-scale $\mathrm{H} / \mathrm{He}$ filled cavities at grain boundary link up and shear of bridges in between.

The limited literature references surveyed above give some ideas about mechanisms involved in the fractures.

\subsubsection{Type 1 -Brittle Intergranular Fracture}

Type 1a. With respect to the RIS process undergone on grain boundaries of ASSs during irradiation, the grain boundary decohesion is anticipated to be the most relevant explanation of IG fracture. The grain boundary cohesion of the irradiated ASSs is affected by RIS, i.e., by the segregation of Ni and 
$\mathrm{Si}$ and $\mathrm{Cr}$ depletion. Approximately, the influence of RIS on the GB cohesion can be estimated using the data on the strengthening/embrittling energy $\left(\Delta \mathrm{E}_{\mathrm{SE}, \mathrm{I}}\right)$ and the grain boundary concentrations of individual solutes (cf. Equation (14) in [46]). For the first estimate of the effect of individual solutes, we may use the value of $\Delta \mathrm{E}_{\mathrm{SE}, \mathrm{I}}=-106 \mathrm{~kJ} / \mathrm{mol}$ for $\mathrm{Cr}$ in austenitic iron [47] and suppose that the effect of $\mathrm{Si}$ and $\mathrm{Ni}$ on the cohesion of grain boundaries in austenite is similar to that in ferritic iron, i.e., $\Delta \mathrm{E}_{\mathrm{SE}, \mathrm{I}}=-7 \mathrm{~kJ} / \mathrm{mol}$ for $\mathrm{Si}$ and $\Delta \mathrm{E}_{\mathrm{SE}, \mathrm{I}}=-20 \mathrm{~kJ} / \mathrm{mol}$ for $\mathrm{Ni}[46]$ (no data on $\Delta \mathrm{E}_{\mathrm{SE}, \mathrm{I}}$ have been published about these solutes in austenite till now). Whereas the depletion of $\mathrm{Cr}$ is large, it causes reduction of the GB cohesion of the austenite. Slight segregation of Si has a negligible effect on cohesion while that of $\mathrm{Ni}$ can cause a mild increase of the cohesion only. As a result, we can accept that the dominant effect is that of $\mathrm{Cr}$ while the effect of $\mathrm{Si}$ and $\mathrm{Ni}$ is negligible.

This segregation process is similar to segregations occurring during thermal sensitization of the un-irradiated ASSs, as had been widely referred (e.g., [48-50]). It resulted in weakening of grain boundary cohesion and a tendency of IG fractures at low temperatures as well as in high temperature water environments. The relationship between thermally induced $\mathrm{Cr}$ depletion and IGSCC were reported [5]. However, it has been observed that the role of the GB crystallography was likely secondary and the GB normal stress (higher than the yield strength) played the primary role in IGSCC initiation in the sensitized A304 steel, even if the proportion of the cracked low indexed GB planes (20\%) was higher than the one (12\%) in a random selection [51]. The chemical composition and the presence of carbides in the GB was likely decisive, but further observation and analyses are necessary for predictive models. In parallel, GB cohesive strength (intergranular normal stress) lower than $100 \mathrm{MPa}$ (lower than the yield strength) resulted from recent modeling of the IG fracture process in the irradiated steels and the value was decreasing with increasing dose [52], suggesting a tendency of decohesion.

On the other hand, there was not yet any direct evidence for the fracture mechanism in irradiated ASSs even if the pure IG fractures observed at impact tests at $-196{ }^{\circ} \mathrm{C}$ [17] might be the case. The fracture character of in-service irradiated $18 \mathrm{Cr}-10 \mathrm{Ni}-\mathrm{Ti}$ [3] and CW316L of FTT [17] changed from fully ductile dimples at RT to $90 \%$ IG at very low temperature about $-100{ }^{\circ} \mathrm{C}$. Reasons for the change are not clear, nor is it clear whether IG fracture occurs by an atomically brittle mode (Type 1, Figure 1a) or by MVC process (Type 2, Figure 1b). In 18Cr-10Ni-Ti [3], the low T IG fracture occurred in all the three levels of irradiation. The $2.4 \mathrm{dpa}$ material did not contain cavities distinguishable by standard TEM, but the other 5.2 and $11.2 \mathrm{dpa}$ ones had about $2 \mathrm{~nm}$ fine cavities of void swelling in amounts much lower than $0.1 \%$. The occurrence of IG fracture of the 2.4 dpa specimen show that the low temperature IG fracture does not need the presence of the fine voids. Moreover, the IG fracture cannot be triggered from large $\delta$-ferrite particles occurring close to GB (Figure 7c), because there is a large difference between $1-7 \% \delta$-ferrite fraction in the steel and nearly $90 \%$ fraction of IG facets on the fractures. Further microscopic analyses are needed to confirm brittle or ductile fine features of the IG planes.

Type 1b. According to some theories [48], the changed microchemistry of grain boundary of non-irradiated ASSs could increase locally the temperature of the martensite transformation above room temperature. Then the strain-induced martensite can form preferentially in the precipitate free zone. In [53], there was for a first time an investigated phase transformation around grain boundaries of irradiated ASSs. Orientation imaging microscopy-electron backscatter diffraction (OIM-EBSD) and TEM were employed to investigate the structure of those materials and the morphology of strain induced martensite. The specimens of a high-purity commercial AISI 304 stainless steel had been irradiated in the BOR-60 fast reactor to $4.4-10.2 \mathrm{dpa}$ at $320^{\circ} \mathrm{C}$. The observation revealed that (i) the irradiation decreased the critical strain required to form martensite and increased the critical stress significantly; (ii) martensite formed along slip lines and also near grain boundaries and (iii) grain orientation strongly influenced martensite formation. But, the type of fracture was not provided. On the other hand, in 18Cr-10Ni-Ti steel in-service WWER irradiated to $5.2 \mathrm{dpa}$, twins and martensite needles were observed in the microstructure after tensile test by $6 \times 10^{-4} \mathrm{~s}^{-1}$ in air (Figure 16a). On the fracture surface of the specimen, dimples and shear plane appeared, but no IG fracture (Figure 16b). 
The other study on the 30 dpa irradiated A304 stainless steel referred that IG fracture was observed after slow tensile testing in argon gas of $340{ }^{\circ} \mathrm{C}$ and also some strain martensite was found in the microstructure [42].

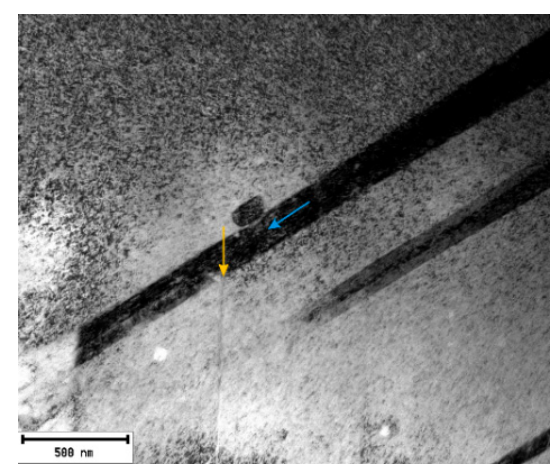

(a)

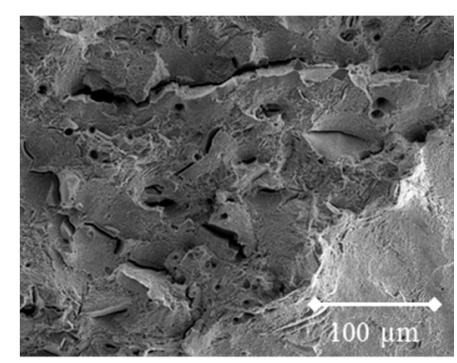

(b)

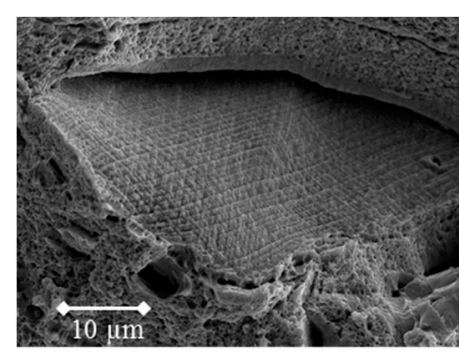

(c)

Figure 16. The $18 \mathrm{Cr}-10 \mathrm{Ni}$-Ti steel in-service WWER irradiated to $5.2 \mathrm{dpa}$ after tensile test at RT: (a) microstructure below fracture showing twins (yellow arrow) and strain martensite needles (blue arrow) [6]; Copyright 2017 by The Minerals, Metals \& Materials Society. Used with permission; (b) fracture surface showing mix of dimples, secondary cracks and TG facets and (c) detail of the facet.

In the case of the $20 \% \mathrm{CW}$ A316 irradiated at intermediate $\mathrm{T}\left(385{ }^{\circ} \mathrm{C}\right)$ contained $\sim 3-8 \%$ void swelling [33], it was reported that intensive RIS underwent on the void/matrix interfaces and resulted in extensive formation of ferritic phase, $\varepsilon$-martensite micro-platelets, owing to a substantial decrease in SFE. The strain martensite was observed in the matrix after tensile and fracture toughness testing by TEM. The $\gamma / \varepsilon$ boundaries provided a low energy path for crack propagation, producing a very brittle failure referred to as quasi-cleavage (Figure 13).

Type 1c. Brittle intergranular fracture had been referred in irradiated ASSs in connection to the He embrittlement. It is stated in [54] that, below $550{ }^{\circ} \mathrm{C}$, the IG fracture of Type 316 neutron irradiated containing He was correlated with edge-to-edge He bubbles spacing closer than $8 \mathrm{~nm}$ and bubble diameter. At temperatures higher than $550^{\circ} \mathrm{C}$ [54,55], IG fracture was observed regardless of He spacing. Recently [18], the grain boundary fractures were studied in room temperature He-ion irradiated $15 \% \mathrm{CW} 316 \mathrm{~L}$ specimens using in-situ testing with micro-size tensile specimens FIB fabricated across grain boundaries. The findings revealed that He promotes GB fracture by weakening the GB strength and hardening the matrix due to the formation of He bubbles both on GBs and in the matrix. It was suggested that GB segregated He atoms may have a role in GB fracture. Specifically, in the He-ion irradiated specimens, the brittle intergranular fracture occurred if He concentrations were above 2 at. \%, He bubble spacing on GB became smaller than $5 \mathrm{~nm}$ and GB coverage more than 6\%. However, the fracture micrographs presented there show that the brittle fractured GB areas were not flat, but having fine features arranged into a network that could correspond to bubbles of average size of about $2 \mathrm{~nm}$ (Figure 17). 


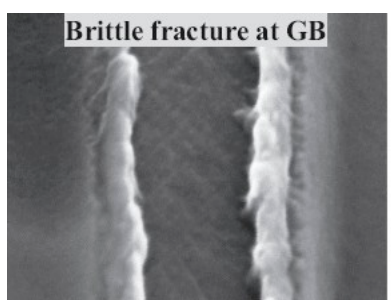

(a)

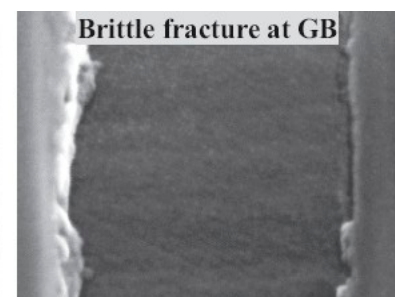

(b)

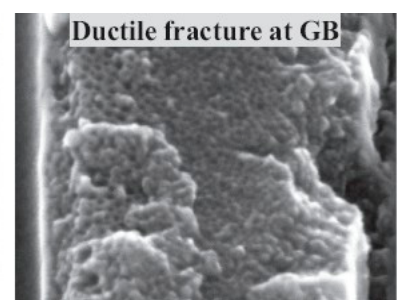

(c)

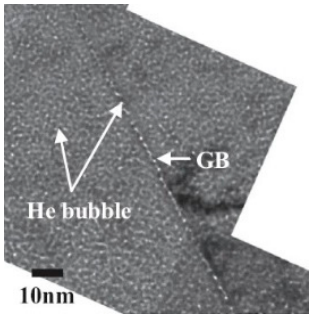

(d)

Figure 17. Unique SEM micrographs of grain boundary (GB) fracture of micro-tensile specimens of He-ion irradiated $15 \% \mathrm{CW} 316 \mathrm{~L}$, in a $45^{\circ}$ perspective view: (a) $2 \% \mathrm{He}$; (b) $10 \% \mathrm{He}$; (c) $10 \% \mathrm{He}$ post-irradiation annealed at $923 \mathrm{~K}$; (d) $6 \% \mathrm{He}$ [18]. Reproduced with courtesy of K. Fukuya. Elsevier reuse license has been granted.

The idea of the atomically brittle intergranular fracture was proposed as an explanation for the observed intergranular fracture of the $80 \mathrm{dpa}$ internals and $65 \mathrm{dpa}$ FTT at room temperature $[19,20]$. The authors expected the presence of He-bubbles on grain boundaries resulting in intergranular embrittlement [19] based on previous experience [18,54]. The amount of void swelling of the materials was not given in the paper, but according to an estimation presented in [18], the He production rate in similar FTT is about $10 \mathrm{ppm} / \mathrm{dpa}$; it is 0.08 at. \% He for the $80 \mathrm{dpa}$ material. As given above, this value is likely too low to cause the brittle IG fracture.

\subsubsection{Type 2-Ductile Intergranular Fracture}

In the literature data surveyed above, there were given examples of the all sub-types.

Type 2a. As mentioned above, the IG fracture character of $18 \mathrm{Cr}-10 \mathrm{Ni}-\mathrm{Ti}$ [3] and CW316L [17] at very low temperature below $-100^{\circ} \mathrm{C}$ may be explained by Type 1a as well or Type 2a mechanisms. For sure, the IG planes are not featureless and may contain very fine dimples. But, further microscopic analyses are needed to confirm brittle or ductile fine features of the IG planes of the low T IG fractures [3,17]. The mechanism of nano-scale dimpled intergranular fracture (Figure $1 \mathrm{~b}$ ) resulting from twinning limited to grain boundary region is supported by the direct observation of twinning at grain boundary, Figure $7 \mathrm{~b}$, and by the other low T IG fractures under the LTHR condition [17]. This mechanism is consistent with the shift in dominancy of plastic deformation modes of calculated deformation maps [36,56].

Type $2 \mathrm{~b}$. The images of the fracture of $18 \mathrm{Cr}-10 \mathrm{Ni}$-Ti intermediate $\mathrm{T}$ irradiated specimens tested at $\mathrm{RT}$ and $290^{\circ} \mathrm{C}$ (Figure 12) are not available at higher magnification, but likely some channel fracture or cleavage planes mixed with IG could be identified even at lower magnification.

\subsubsection{Irradiation Assisted SCC Fracture}

The IASCC degradation process is a consequence of the corrosion reaction on the metal surface with an oxide scale development that either facilitates decohesion or stimulates the process of nano-cavities formation and coalescence on grain boundary under stress. Accordingly, the character of the intergranular fracture of IASCC may be brittle or ductile in nano-scale. Here it should be noted that the segregation and strain rate issues might be applicable also to IASCC fractures. Hydrogen atoms resulting from corrosion reactions penetrate from the surface into bulk and may segregate on GBs and other interfaces. However, no experimental data of $\Delta \mathrm{E}_{\mathrm{SE}, \mathrm{I}}$ are available. Moreover, the appearance of IG facets of IASCC often has fine features (Figure 9), likely fine dimples, that the fracture mode might describe better the scheme of Figure $1 \mathrm{~b}$ than the one of Figure 1a. In recent years, localized deformation has gained attention as a potential contributor to IASCC [28]. The correlation of localized deformation with IASCC initiation, in proton irradiated ASS tested in BWR, was found to be significantly higher than others [28], i.e., stacking fault energy, hardness and chromium content at grain boundary. Localized deformation may be the most important factor in IASCC; it may promote 
the cracking through intensive interaction of dislocations in slip channels with grain boundaries. A relationship between strain localized in dislocation channels and crystallographic structure of grain boundaries was studied on proton irradiated 316L stainless steel [57]. The consistent occurrence of strain in-compatibilities, i.e., dislocation channels arrested at grain boundaries at the sites of crack initiation, suggested that it might promote IG cracking. When slip discontinuity occurred at GB, localized GB sliding was observed at the site. The slip discontinuity was more prevalent on GHAB along grains which underwent strain owing to suitable orientation to load axis. In [58,59], there were given detailed insights of IASCC initiation of A304L irradiated in BOR-60 at $320{ }^{\circ} \mathrm{C}$ to $5.5 \mathrm{dpa}$. It was referred that, to initiate IG cracks, the applied stress was lower than the yield strength, but dislocation channels and MnS inclusions were observed around GB, where the IASCC cracks initiated. It was observed that crystallographic structure of GBs is decisive for IASCC crack propagation, e.g., in a study on the neutron irradiated specimens of type 304 ASS (JMTR, 1 dpa) tested in high temperature water simulating BWR [60]. The intergranular cracks of IASCC propagated mainly along GHAB. These facts indicate rather ductile than brittle character of IASCC intergranular fracture, i.e., Type 2 fracture mechanism.

\subsection{Ductile-To-Brittle Transition}

In general, ductile-to-brittle transition (DBT) behaviors correspond to brittle fractures appearance transition temperature regardless of the kinetics of loading. The corresponding IG fracture mechanism might fall under Type 1. DBT represents well known phenomena in ferritic steels. However, the fracture mode transition, from ductile dimpled to brittle IG, as a function of heat treatment was observed for non-irradiated steel A316 in impact tests at RT [48]; the sensitized ASS failed by IG fracture owing to weakening of GB by $\mathrm{Cr}$ depletion and extensive carbide precipitation.

The radiation changes of material behavior that caused the quasi cleavage fracture at RT and the channel fracture at higher temperatures observed in A316 containing more than 3\% void swelling [33] very likely indicate DBT behavior. In the irradiated ASS containing bubbles of Helium and a respectively higher level of void swelling, the chemical changes around the voids led to local transformation into ferrite microstructure. In parallel, the fracture character of the immediate and high T irradiated 18Cr-10Ni-Ti ASSs $[34,35]$ might also indicate the features of DBT behavior. The fractures of the specimens of more than $15-20 \%$ void swelling were quasi-cleavage with essentially zero plasticity.

A possibility of DBT behavior in thermal reactor-service ASS irradiated to high dpa levels ( $>20$ dpa) might be resolved through identifying of the fine character of the IG fractures. At present, all the mentioned cases of IG fractures of the low T irradiated ASSs may be explained with the same weight by Type 1 as well as Type 2 . The occurrence of intergranular fracture in internal components at room and in lower temperatures $[3,17,19,20]$ can be explained by the change of plastic behavior, i.e., occurrence of twinning on and around GB, and also by decohesion owing to RIS. Unambiguous proofs of the Type 1 fracture mechanism are required before one begins to think seriously about DBT behavior. Further examination of irradiated steels focusing on high resolution fractography is necessary to understand the mechanism.

Any existence of DBT in the ASSs with increasing irradiation dose should be clearly proven or disproven, to know if the thermal reactor neutron irradiation really leads to embrittlement manifesting at low temperatures. If yes, all manipulations with very high irradiated ASS components should be treated with a new rule reflecting this behavior. Understanding of character of the intergranular fracture at low temperature is the key point.

\section{Conclusions}

The occurrence of several cases of intergranular fracture of austenitic stainless steels irradiated at various conditions were surveyed in this review.

In the case of the steels which were irradiated at intermediate and high $T_{i r}$, the level of void swelling plays a decisive role in the fracture mechanism. In the case of the level of void swelling higher 
than $3 \%$, quasi-cleavage at low temperature might be expected as well as ductile-to-brittle fracture changes with temperature.

The cases of IG fractures of low temperature irradiated steels exhibiting void swelling lower than $1 \%$ have raised concerns over ductile-to-brittle transition behavior in thermal reactor-service ASS irradiated up to high dpa levels. Studying of the fine character of the IG fracture at low temperatures can provide a valuable insight into this issue.

Analyzing available limited fracture data, arguments were found supporting both the ideas that the intergranular fracture has a brittle character and a nano-scale ductile one. The intergranular fracture occurrence at low temperatures might be correlated with decohesion or twinning and strain martensite transformation in local narrow areas around grain boundaries. The first is a pure brittle process, which may increase the risk of larger damages. The second is a ductile microstructural process influenced by the applied strain rate. It means no risk of unstable fracture as well as open possibility of mitigation.

Further studies are recommended, mainly on fracture kinetics at room and lower temperatures with detailed examination of nanoscale fine fracture features.

Acknowledgments: The presented work was financially supported by the Ministry of Education, Youth and Sport Czech Republic Project LQ1603 (Research for SUSEN). This work has been realized within the SUSEN Project (established in the framework of the European Regional Development Fund (ERDF) in project CZ.1.05/2.1.00/03.0108). The author acknowledges fruitful discussions with Pavel Lejcek.

Conflicts of Interest: The author declares no conflict of interest.

\section{List of Abbreviations}

\begin{tabular}{|c|c|c|c|}
\hline Abbreviation & Name & Abbreviation & Name \\
\hline BWR & Boiling Water Reactor & PFZ & Precipitate Free Zone \\
\hline CT & Compact Tension specimen & RCI & Reactor Core Internals \\
\hline $\mathrm{CW}$ & Cold Work & $\mathrm{RD}$ & Radiation Damage \\
\hline EBR & Experimental Breeder Reactor & SCC & Stress Corrosion Cracking \\
\hline EDS & Energy-dispersive $X$-ray spectroscopy & & \\
\hline FTT & Flux thimble tubes & SEM & Scanning Electron Microscopy \\
\hline HTLR & High T Low-strain Rate & SFE & Stacking Fault Energy \\
\hline GB & Grain Boundary & TEM & Transmission Electron Microscopy \\
\hline IG & Intergranular & WWER & Russian PWR \\
\hline IGSCC & Intergranular SCC & $\Delta \mathrm{E}_{\mathrm{SE}, \mathrm{I}}$ & Strengthening/embrittling energy \\
\hline JIC & Critical Fracture Resistance & $\Sigma$ & GB crystallography characteristics \\
\hline JMTR & Japan Material Test Reactor & $\alpha$ & Ferrite phase \\
\hline $\mathrm{K}_{\mathrm{IC}}$ & Fracture Toughness & $\alpha^{\prime}, \varepsilon$ & Martensite phase \\
\hline LTHR & Low $\mathrm{T}$ high strain rate & $\gamma$ & Austenite phase \\
\hline LWR & Light Water Reactor & & \\
\hline
\end{tabular}

\section{References}

1. Bruemmer, S.M.; Charlot, L.A.; Atteridge, D.G. Sensitization development in austenite stainless steel-measurement and prediction of thermo-mechanical history effects. Corrosion 1988, 44, 427-434. [CrossRef]

2. Lynch, S.P. Mechanisms of intergranular fracture. Mater. Sci. Forum 1989, 46, 1-24. [CrossRef] 
3. Hojna, A. Intergranular Fracture and Fracture Toughness of Irradiated Austenitic Stainless Steels of Reactor Core Internals. In Proceedings of the 16th International Symposium on Environmental Degradation of Materials in Nuclear Power Systems-Water Reactors, Ashville, NC, USA, 11-15 August 2013; NACE: Houston, TX, USA, 2014.

4. Nastasi, M.; Mayer, J.W.; Hirvonen, J.K. Ion-Solid Interactions. In Ion-Solid Interactions: Fundamentals and Applications; Cambridge University Press: Cambridge, UK, 1996; ISBN 052137376X.

5. Bruemmer, S.M.; Simonen, E.P.; Scott, P.M.; Andresen, P.L.; Was, G.S.; Nelson, J.L. Radiation-induced material changes and susceptibility to intergranular failure of light-water-reactor core internals. J. Nucl. Mater. 1999, 274, 299-314. [CrossRef]

6. Hojna, A.; Duchon, J.; Halodova, P.; Namburi, H.K. Effect of Strain Rate and High Temperature Water on Deformation Structure of Vver Neutron Irradiated Core Internals Steel. In Proceedings of the 18th International Symposium on Environmental Degradation of Materials in Nuclear Power Systems-Water Reactors, Portland, OR, USA, 13-17 August 2017; The Minerals, Metals \& Materials Society: Warrendale, PA, USA, 2018.

7. Kim, J.W.; Byun, T.S. Analysis of tensile deformation and failure in austenitic stainless steels: Part I-Temperature dependence. J. Nucl. Mater. 2010, 396, 1-9. [CrossRef]

8. Kim, J.W.; Byun, T.S. Analysis of tensile deformation and failure in austenitic stainless steels: Part II-Irradiation dose dependence. J. Nucl. Mater. 2010, 396, 10-19. [CrossRef]

9. Bloom, E.E.; Weir, J.R., Jr. Effect of neutron irradiation on the ductility of austenitic stainless steel. Nucl. Technol. 1972, 16, 45-54. [CrossRef]

10. Nelson, J.L.; Gorman, J.A.; Pathania, R.; Busby, J. Development of Potential Radiation Resistant Alloys for Use in LWRs. In Proceedings of the 16th International Symposium on Environmental Degradation of Materials in Nuclear Power Systems-Water Reactors, Ashville, NC, USA, 11-15 August 2013; NACE: Houston, TX, USA, 2014.

11. Chopra, O.K.; Rao, A.S. A review of irradiation effects on LWR core internal materials-Neutron embrittlement. J. Nucl. Mater. 2011, 412, 195-208. [CrossRef]

12. Fyfitch, S.; Xu, H.; Demma, A.; Carter, R.; Gamble, R.; Scott, P. Fracture Toughness of Irradiated Stainless Steel in Nuclear Power Systems. In Proceedings of the 14th International Symposium on Environmental Degradation of Materials in Nuclear Power Systems-Water Reactors, Virginia Beach, VA, USA, 23-27 August 2009; American Nuclear Society (ANS): Cook County, IL, USA, 2010; pp. 1307-1313.

13. Hojna, A.; Ernestova, M.; Hietanen, O.; Korhonen, R.; Hulinova, L.; Oszvald, F. Irradiation Assisted Stress Corrosion Cracking of Austenitic Stainless Steel WWER Reactor Core Internals. In Proceedings of the 15th International Symposium on Environmental Degradation of Materials in Nuclear Power Systems-Water Reactors, Colorado Springs, CO, USA, 7-11 August 2011; The Minerals, Metals \& Materials Society: Warrendale, PA, USA, 2011.

14. Lucas, G.E.; Billone, M.; Pawel, J.E.; Hamilton, M.L. Implications of radiation-induced reductions in ductility of austenitic stainless steel structures. J. Nucl. Mater. 1996, 233-237, 207-212. [CrossRef]

15. Manahan, M.P.; Kohli, R.; Santucci, J.; Sipush, P. A Phenomenological investigation of in-reactor cracking of type 304 stainless steel control rod cladding. Nucl. Eng. Des. 1989, 113, 297-321. [CrossRef]

16. Fukuya, K.; Nishioka, H.; Fujii, K.; Kamaya, M.; Miura, T.; Torimaru, T. Material Property Changes of Stainless Steels under PWR Irradiation. In Proceedings of the International Congress on Advances in Nuclear Power Plants 2009 (ICAPP 2009), Tokyo, Japan, 10-14 May 2009.

17. Fukuya, K.; Nishioka, H.; Fujii, K.; Kamaya, M.; Miura, T.; Torimaru, T. Fracture behavior of austenitic stainless steels irradiated in PWR. J. Nucl. Mater. 2008, 378, 211-219. [CrossRef]

18. Miura, T.; Fujii, K.; Fukuya, K. Micro-mechanical investigation for effects of helium on grain boundary fracture of austenitic stainless steel. J. Nucl. Mater. 2015, 457, 279-290. [CrossRef]

19. Jenssen, A.; Efsing, P.; Forssgren, B.; Bengtsson, B.; Molin, M. Examination of Highly Irradiated Stainless Steels from BWR and PWR Reactor Pressure Vessel Internals. In Proceedings of the 7th International Symposium on Contributions of Materials Investigation to Improve the Safety and Performance of PWRs (Fontevraud 7), Avignon, France, 26-30 September 2010; Société Française d'Énergie Nucléaire (SFEN): Paris, France, 2010. 
20. Jenssen, A.; Grigoriev, V.; Jakobsson, R.; Efsing, P. Fracture Resistance Evaluation of a Flux Thimble Irradiated to 65 Dpa in a PWR. In Proceedings of the 6th International Symposium on Contributions of Materials Investigation to Improve the Safety and Performance of PWRs (Fontevraud 6), Fontevraud, France, 18-22 September 2006; Société Française d'Énergie Nucléaire (SFEN): Paris, France, 2006.

21. Matsuoka, T.; Yamaguchi, Y.; Yonezawa, T.; Nakamura, K.; Fukuda, R.; Shiraishi, S. Irradiation assisted mechanical cracking on cladding tubes of control rods in nuclear reactors. JSME Int. J. A 1999, 42, 438-446. [CrossRef]

22. Fukuya, K.; Nakano, M.; Fujii, K.; Torimaru, T. IASCC susceptibility and slow tensile properties of highly-irradiated 316 stainless steels. J. Nucl. Sci. Technol. 2004, 41, 673-681. [CrossRef]

23. Connerman, J.; Shogan, R.; Fujimoto, K.; Yonezawa, T.; Yamaguchi, Y. Irradiation Effects in a Highly Irradiated Cold Worked Stainless Steel Removed From A Commercial PWR. In Proceedings of the 12th International Conference on Environmental Degradation of Materials in Nuclear Power Systems-Water Reactors, Salt Lake City, UT, USA, 14-18 August 2005; Allen, T.R., King, P.J., Nelson, L., Eds.; TMS (The Minerals, Metals \& Materials Society): Warrendale, PA, USA, 2005; pp. 277-284.

24. Nishioka, H.; Fukuya, K.; Fujii, K.; Torimaru, T. IASCC Properties And Mechanical Behavior of Stainless Steels Irradiated up to $73 \mathrm{dpa}$. In Proceedings of the 13th International Conference on Environmental Degradation of Materials in Nuclear Power Systems, Whistler, BC, Canada, 19-23 August 2007.

25. Fukuya, K. Current understanding of radiation-induced degradation in light water reactor structural materials. J. Nucl. Sci. Technol. 2013, 50, 213-254. [CrossRef]

26. Toivonen, A.; Aaltonen, P.; Karlsen, W.; Ehensten, U.; Massoud, J.-P.; Bouesier, J.-M. Post-Irradiation SCC Investigations on Highly-Irradiated Core Internals Component Materials. In Proceedings of the 6th International Symposium on Contributions of Materials Investigation to Improve the Safety and Performance of PWRs (Fontevraud 6), Fontevraud, France, 18-22 September 2006; Société Française d'Énergie Nucléaire (SFEN): Paris, France, 2006.

27. Was, G.S. Recent Developments in Understanding Irradiation Assisted Stress Corrosion Cracking. In Proceedings of the 11th International Conference Environmental Degradation of Materials in Nuclear Systems, Skamania Lodge, WA, USA, 10-14 August 2003; pp. 965-984.

28. Jiao, Z.; Was, G.S. Impact of localized deformation on IASCC in austenitic stainless steels. J. Nucl. Mater. 2011, 408, 246-256. [CrossRef]

29. Lucas, G.E. The evolution of mechanical property change in irradiated austenitic stainless steels. J. Nucl. Mater. 1993, 206, 287-305. [CrossRef]

30. Fish, R.L.; Straalsund, J.L.; Hunter, C.W.; Holmes, J.J. Swelling and Tensile Property Evaluations of High-fluence EBR-II Thimbles. In Effects of Radiation on Substructure and Mechanical Properties of Metals and Alloys; STP529; ASTM: Philadelphia, PA, USA, 1973; pp. 149-164.

31. Garner, F.A. Radiation Damage in Austenitic Steels. In Comprehensive Nuclear Materials; Elsevier: Amsterdam, The Netherlands, 2012; Volume 4, pp. 33-95.

32. Huang, F.H. The fracture characterization of highly irradiated Type 316 stainless steel. Int. J. Fract. 1984, 25, 181-193. [CrossRef]

33. Hamilton, M.L.; Huang, F.H.; Yang, W.J.S.; Garner, F.A. Mechanical Properties and Fracture Behavior of 20\% Cold-Worked 316 Stainless Steel Irradiated to Very High Neutron Exposures. In Influence of Radiation in Material Properties: 13th International Symposium (Part II); Garner, F.A., Henager, C.H., Jr., Igata, N., Eds.; ASTM STP 956; ASTM: Philadelphia, PA, USA, 1987; pp. 245-270.

34. Margolin, B.Z.; Kursevich, I.P.; Sorokin, A.A.; Neustroev, V.S. The Relationship of Radiation Embrittlement and Swelling for Austenitic Steel for WWER Internals. In Proceedings of the ASME 2009 Pressure Vessels and Piping Conference, Prague, Czech Republic, 26-30 July 2009; ASME: Philadelphia, PA, USA, 2009.

35. Neustroev, V.S.; Garner, F.A. Severe embrittlement of neutron irradiated austenitic steels arising from high void swelling. J. Nucl. Mater. 2009, 386-388, 157-160. [CrossRef]

36. Zinkle, S.J. Fusion materials science: Overview of challenges and recent progress. Phys. Plasmas 2005, 2, 058101. [CrossRef]

37. Bruemmer, S.M.; Cole, J.I.; Brimhall, J.L.; Carter, R.D.; Was, G.S. Radiation Hardening Effects on Localized Deformation and Stress Corrosion Cracking of Stainless Steels. In Proceedings of the 6th International Symposium on Environmental Degradation of Materials in Nuclear Power Systems-Water Reactors, San Diego, CA, USA, 3-5 August 1993; pp. 537-546. 
38. Hashimoto, N.; Zinkle, S.J.; Rowclife, A.F.; Robertson, J.P.; Jitsukawa, S. Deformation mechanisms in 316 stainless steel irradiated at $60^{\circ} \mathrm{C}$ and $330^{\circ} \mathrm{C}$. J. Nucl. Mater. 2000, 283-287, 528-534. [CrossRef]

39. Talonen, J. Effect of Strain-induced $\alpha^{\prime}$-martensite Transformation on Mechanical Properties of Metastable Austenitic Stainless Steels. Ph.D. Thesis, Helsinki University of Technology, Helsinki, Finland, 2007.

40. Gusev, M.N.; Maksimkin, O.P.; Garner, F.A. Peculiarities of plastic flow involving "deformation waves" observed during low-temperature tensile tests of highly irradiated 12Cr18Ni10Ti and 08Cr16Ni11Mo3 steels. J. Nucl. Mater. 2010, 403, 121-125. [CrossRef]

41. Gusev, M.N.; Maksimkin, O.P.; Osipov, I.S.; Garner, F.A. Anomalously large deformation of $12 \mathrm{Cr} 18 \mathrm{Ni10Ti}$ austenitic steel irradiated to $55 \mathrm{dpa}$ at $310^{\circ} \mathrm{C}$ in the BN-350 reactor. J. Nucl. Mater. 2009, 386-388, 273-276. [CrossRef]

42. Karlsen, W.; Pakarinen, J.; Toivonen, A.; Ehrnstén, U. Deformation microstructures of 30 dpa AISI 304 stainless steel after monotonic tensile and constant load autoclave testing. In Proceedings of the 15th International Symposium on Environmental Degradation of Materials in Nuclear Power Systems-Water Reactors, Colorado Springs, CO, USA, 7-11 August 2011; TMS: Warrendale, PA, USA, 2011.

43. Lejček, P. Grain Boundary Segregation in Metals, 1st ed.; Springer Series in Material Science 136; Springer: Berlin/Heidelberg, Germany, 2010; ISBN 978-3-642-12504-1.

44. West, E.A.; Was, G.S. IGSCC of grain boundary engineered 316L and 690 in supercritical water. J. Nucl. Mater. 2009, 392, 264-271. [CrossRef]

45. Lehockey, E.M.; Brennenstuhl, A.M.; Thompson, I. On the relationship between grain boundary connectivity, coincident site lattice boundaries, and intergranular stress corrosion cracking. Corros. Sci. 2004, 46, 2383-2404. [CrossRef]

46. Lejček, P.; Šob, M.; Paidar, V. Interfacial segregation and grain boundary embrittlement: An overview and critical assessment of experimental data and calculated results. Prog. Mater. Sci. 2017, 87, 83-139. [CrossRef]

47. Yang, R.; Zhao, D.L.; Wang, Y.M.; Wang, S.Q.; Ye, H.Q.; Wang, C.Y. Effects of Cr, Mn on the cohesion of the $\gamma$-iron grain boundary. Acta Mater. 2001, 49, 1079-1085. [CrossRef]

48. Bruemmer, S.M. Grain boundary chemistry and intergranular failure of austenitic stainless steels. Mater. Sci. Forum 1989, 46, 309-334. [CrossRef]

49. Simmons, J.W.; Atteridge, D.G.; Bruemmer, S.M. Continuous cooling sensitization of type 316 austenitic stainless steel. Corrosion 1992, 48, 976-982. [CrossRef]

50. Kilian, R.; Brümmer, G.; Ilg, U.; Meier, V.; Teichmann, H.; Wachter, O. Characterization of Sensitization and Stress Corrosion Cracking Behavior of Stabilized Stainless Steels under BWR-Conditions. In Proceedings of the 7th International Symposium on Environmental Degradation of Materials in Nuclear Power Systems-Water Reactors, Breckenridge, CO, USA, 6-10 August 1995; Airey, G., Andresen, P., Brown, J., Eds.; NACE: Houston, TX, USA, 1995; Volume 2, pp. 529-538.

51. Stratulat, A.; Duff, J.; Marrow, T.J. Grain boundary structure and intergranular stress corrosion crack initiation in high temperature water of a thermally sensitised austenitic stainless steel observed in situ. Corros. Sci. 2014, 85, 428-435. [CrossRef]

52. Hure, J.; El Shawish, S.; Cizelj, L.; Tanguy, B. Intergranular stress distributions in polycrystalline aggregates of irradiated stainless steel. J. Nucl. Mater. 2016, 476, 231-242. [CrossRef]

53. Gussev, M.N.; Busby, J.T.; Byun, T.S.; Tan, L. Phase stability of highly irradiated austenitic alloys during deformation. In Proceedings of the 16th International Symposium on Environmental Degradation of Materials in Nuclear Power Systems-Water Reactors, Ashville, NC, USA, 11-15 August 2013; NACE: Houston, TX, USA, 2013.

54. Bennetch, J.I.; Jesser, W.A. Microstructural aspects of He embrittlement in type 316 stainless steel. J. Nucl. Mater. 1981, 104, 809-813. [CrossRef]

55. Nogami, S.; Hasegawa, A.; Tanno, T.; Imasaki, K.; Abe, K. High-temperature helium embrittlement of 316FR steel. J. Nucl. Sci. Technol. 2011, 48, 130-134. [CrossRef]

56. Byun, T.S.; Hashimoto, N.; Farrell, K. Deformation mode map of irradiated 316 stainless steel in true stress-dose space. J. Nucl. Mater. 2006, 351, 303-315. [CrossRef]

57. West, E.A.; Was, G.S. Strain incompatibilities and their role in intergranular cracking of irradiated 316L stainless steel. J. Nucl. Mater. 2013, 441, 623-632. [CrossRef]

58. Stephenson, K.J.; Was, G.S. Crack initiation behavior of neutron irradiated model and commercial stainless steels in high temperature water. J. Nucl. Mater. 2014, 444, 331-341. [CrossRef] 
59. Stephenson, K.J.; Was, G.S. The role of dislocation channeling in IASCC initiation of neutron irradiated stainless steel. J. Nucl. Mater. 2014, 481, 214-225. [CrossRef]

60. Kaji, Y.; Kondo, K.; Aoyagi, Y.; Kato, Y.; Taguchi, T.; Takada, F.; Nakano, J.; Ugachi, H.; Tsukada, T.; Takakura, K.; et al. Stress Corrosion Cracking Behavior of Type 304 Stainless Steel Irradiated under Different Neutron Dose Rates at JMTR. In Proceedings of the 15th International Symposium on Environmental Degradation of Materials in Nuclear Power Systems-Water Reactors, Colorado Springs, CO, USA, 7-11 August 2011; TMS: Warrendale, PA, USA, 2011.

(C) 2017 by the author. Licensee MDPI, Basel, Switzerland. This article is an open access article distributed under the terms and conditions of the Creative Commons Attribution (CC BY) license (http:// creativecommons.org/licenses/by/4.0/). 